\title{
Do defense mechanisms vary according to the psychiatric disorder?
} Os mecanismos de defesa se modificam de acordo com o transtorno psiquiátrico?

\author{
Carolina Blaya,, ${ }^{1,2}$ Marina Dornelles, ${ }^{1,2}$ Rodrigo Blaya, ${ }^{1,2}$ Leticia Kipper, $^{1,2}$ Elizeth Heldt, 1,2 \\ Luciano Isolan, ${ }^{1,2}$ Michael Bond, ${ }^{3}$ Gisele Gus Manfro ${ }^{1,2}$
}

\begin{abstract}
Objective: The aim of this study was to evaluate the defense mechanisms used by depressive and anxious patients without comorbidities compared to those used by controls and to determine whether these patterns differ between diagnoses. Method: The sample was composed of 167 psychiatric patients and 36 controls that were evaluated using the Defense Style Questionnaire 40. All subjects were evaluated through a clinical interview, and each evaluation was confirmed through the application of the Mini International Neuropsychiatric Interview, a structured psychiatric interview. We used ANOVA and discriminant analysis to assess differences between groups. Results: Neurotic defense mechanisms discriminated controls from all patients except those with social anxiety. Immature defense mechanisms differentiated controls from all patients, as well as distinguished depressive patients from panic disorder and obsessive disorder patients. The discriminant analysis indicated that depressive patients are characterized by projection, panic disorder patients by sublimation and obsessive-compulsive patients by acting out. Conclusions: Depressive and anxious patients differ from other individuals in their use of defense mechanisms, and each diagnosis has a particular pattern. These findings could lead to the development of specific psychotherapeutic interventions.
\end{abstract}

Keywords: Mental disorders; Defense mechanisms; Questionnaires; Personality tests; Depression

\begin{abstract}
Resumo
Objetivo: O objetivo do estudo é avaliar o uso dos mecanismos de defesa utilizados por pacientes deprimidos e ansiosos sem comorbidades comparados com aqueles utilizados por pacientes-controle e se esses padrões de defesa podem ser diferenciados entre os diagnósticos. Método: 167 pacientes psiquiátricos e 36 controles foram avaliados pelo Defense Style Questionnaire 40. Todos os indivíduos foram avaliados por uma entrevista clínica que foi confirmada pelo Mini International Neuropsychiatric Interview, uma entrevista psiquiátrica estruturada. Para detectar diferenças entre os grupos, os dados foram submetidos à análise discriminante e ANOVA. Resultados: As defesas neuróticas discriminam os controles de todos pacientes, exceto dos pacientes com ansiedade social. As defesas imaturas diferenciam os controles de todos pacientes, além de discriminar os pacientes deprimidos dos pacientes com transtorno do pânico e obsessivo. A análise discriminante indica que a projeção diferencia pacientes deprimidos, sublimação diferencia pacientes com transtorno do pânico, e acting-out diferencia pacientes obsessivos-compulsivos. Conclusões: Os pacientes diferem dos controles no uso dos mecanismos de defesa, e cada patologia tem seu padrão particular. Esses achados podem permitir o desenvolvimento de intervenções específicas no tratamento psicoterápico.
\end{abstract}

Descritores: Transtornos psiquiátricos; Mecanismos de defesa; Questionários; Teste de personalidade; Depressão

1 Post-Graduate Program in Medical Sciences, Psychiatry, Universidade Federal do Rio Grande do Sul (UFRGS), Porto Alegre (RS), Brazil 2 Anxiety Disorders Program, Hospital de Clínicas de Porto Alegre, Porto Alegre (RS), Brazil

3 Sir Mortimer B. Davis-Jewish General Hospital and McGill University, Montreal

Financing: Fundação de Incentivo à Pesquisa e Eventos (FIPE), Hospital de Clínicas de Porto Alegre, Centro de Aperfeiçoamento de Pessoal do Ensino Superior (CAPES), Fundação de Amparo à Pesquisa do Rio Grande do Sul (FAPERGS)

Conflict of interests: None

Submitted: 9 April 2006

Accepted: 19 May 2006

\section{Correspondence}

Gisele Gus Manfro

Luis Manoel Gonzaga, 630/11

90470-280 Porto Alegre, RS, Brazil

E-mail: gmanfro@portoweb.com.br 


\section{Introduction}

The defensive style is considered an important dimension of the personality structure of an individual. ${ }^{1}$ It has been related to maturity, health and life adaptiveness. ${ }^{2}$ Vaillant conducted the first clinical studies on the pattern of defense mechanisms by using clinical vignettes obtained from interviews and questionnaires. ${ }^{2}$ He stated that defense mechanisms are arranged along a continuum, from immature to mature defenses, and are used by all individuals regardless of their psychopathology.

The relation between defense mechanisms and psychiatric diagnoses has been studied for many years. ${ }^{3}$ Laplanche and Pontalis suggested that defenses are directly related to psychiatric diagnoses; ${ }^{4}$ whereas Bond and Vaillant proposed that it is a personality aspect that works independently. ${ }^{3}$ The diagnosis refers to the symptoms and pathological behavior; the defenses are related to how people deal with a situation, consciously or unconsciously. Pollock and Andrews showed that there is a specific pattern of defenses associated with each anxiety disorder. ${ }^{5}$ However, there is a lack of data to confirm these results in other studies. ${ }^{3}$ Psychiatric comorbidity might be the bias that contributes to such controversies. Anxiety and affective disorders frequently overlap, and studies are not specific in describing subject comorbidity. ${ }^{5}$ On the other hand, Yuan et al. reported that patients with concomitant anxiety and depression, as well as those with either anxiety or depression, present distinctive defense profiles. ${ }^{6}$

All authors agree that psychiatric patients present defense patterns that are more maladaptive than those observed in controls. ${ }^{7-8}$ Neurotic defenses seem to be associated with anxiety diagnoses, and immature defenses seem to be related to both anxiety and mood disorders. ${ }^{7,9}$ Studies suggest that there is an association between depression and maladaptive defenses, especially the immature defenses, ${ }^{9-12}$ which leads one to believe that immature defenses are more dependent on the depressive state.

Andrews suggested that knowledge of the different defensive patterns can facilitate patient treatment, stating that anxiety disorder patients who have more adaptive defense mechanisms respond to minimal interventions. However, the author also stated that those whose defense mechanisms are more neurotic and immature may require additional treatment. ${ }^{13-14}$ Held et al. showed that panic disorder patients who use more neurotic and immature defenses present poorer outcomes in cognitive behavioral therapy. ${ }^{13}$ A similar result was found for pharmacological treatment. ${ }^{14}$ There is also the possibility that specific defenses might be used to guide specific interventions. For example, a depressed patient who favors reaction formation and altruism may benefit from working as a volunteer. A patient who is acting out might benefit from a clear, consistent and secure therapeutic framework. ${ }^{15}$

The aim of this study was to compare the defense mechanisms of controls to those of depressive and anxious patients without comorbidities in order to determine whether these patterns of defenses differentiate between diagnoses.

\section{Method}

In this cross-sectional study, 350 subjects voluntarily completed the Defense Style Questionnaire 40 (DSQ-40), a 40-question self-report questionnaire. Patients to be included in the study group were randomly selected from psychiatric outpatients seeking treatment from the Anxiety or Depressive Disorders Program of the Hospital de Clínicas de Porto Alegre (HCPA). Patients were grouped according to their primary diagnosis, resulting in four groups: major depressive disorder (MDD), social anxiety disorder (SAD), panic disorder (PD) and obsessive-compulsive disorder (OCD). Those who presented a major comorbidity in any main group were excluded. The control group was made up of 36 HCPA employees without any Axis I psychiatric disorders. Of the 314 patients completing the questionnaire, 194 were excluded due to comorbidity, resulting in 167 study group patients (28 with MDD, 33 with SAD, 79 with PD and 27 with OCD). Therefore, the total sample consisted of 203 subjects.

Subjects were evaluated through clinical interviews and application of the Mini International Neuropsychiatric Interview (MINI - Brazilian version 5.0.0 - DSM-IV), ${ }^{16}$ a standardized and structured diagnostic interview. The MINI, which evaluates the main Axis I psychiatric disorders according to the DSM-IV criteria, is widely used in clinical and research evaluations. ${ }^{17}$ In the present study, all interviews were conducted by trained psychiatrists.

The defense mechanisms were evaluated using the Brazilian Portuguese $^{18}$ version of the DSQ-40,19 in which each defense mechanism is evaluated in two items. Therefore, the DSQ-40 evaluates 20 defenses, which are divided into three factor groups: mature, neurotic and immature. Five defenses are related to the mature factor (sublimation, humor, anticipation, rationalization and suppression); four to the neurotic factor (undoing, pseudoaltruism, idealization and reaction formation) and eleven to the immature factor (projection, passive-aggression, acting out, isolation, devaluation, "autistic fantasy", denial, displacement, dissociation, splitting and somatization) ${ }^{18}$ The individual defense scores are calculated by the average of the two items for each defense mechanism, and the factor scores are the average of the scores of the defenses that belong to each factor.

The study design was approved by the Research Ethics Committee of the HCPA, and all participating subjects gave written informed consent.

\section{Statistical analysis}

Sociodemographic variables are expressed as frequency, mean and standard deviation. The chi-square was used to compare categorical variables and analysis of variance (ANOVA) followed by the Tukey test was used to compare quantitative variables between groups. When there was no homogeneity of variance, Dunnett's T3 multiple comparison test was used. Bonferroni correction was used due to the large number of ANOVAs. In order to identify which defense mechanisms distinguish the four subgroups of patients from the control group, a stepwise discriminant function analysis was performed for all individual defenses. The stepwise analysis selects the most representative variables to construct a model to differentiate the groups.

The analysis was conducted using the Statistical Package for Social Sciences (SPSS), version 12.0. Values of $p<0.05$ were considered statistically significant.

\section{Results}

The sample comprised 140 females and 63 males. The mean age was $38 \pm 11$ years. The gender distribution was comparable among the groups. Depressive patients were significantly older than controls (ANOVA, $p<0.001$ ), although there were no other such age-related differences.

Neurotic defenses discriminated all patients, except the SAD patients, from the controls. In addition, immature defenses differentiated all patients from the controls, as well as distinguishing MDD patients from PD and OCD patients. Active reaction, isolation and rationalization did not differ among the groups. Table 1 depicts the defense mechanisms of patients and controls. 
Table 1 - Defense mechanisms - comparisons among groups (mean \pm standard deviation)

\begin{tabular}{|c|c|c|c|c|c|c|c|}
\hline & $\begin{array}{l}\text { Control } \\
(n=36)\end{array}$ & $\begin{array}{l}\text { Depression } \\
\qquad(n=28)\end{array}$ & $\begin{array}{l}\text { Social phobia } \\
\quad(n=33)\end{array}$ & $\begin{array}{l}\text { Panic disorder } \\
(n=79)\end{array}$ & $\begin{array}{c}\text { OCD } \\
(n=27)\end{array}$ & $\mathbf{F}$ & $\mathbf{p}$ \\
\hline Sublimation & $4.3 \pm 2.0^{a}$ & $5.2 \pm 2.7^{a b}$ & $5.4 \pm 1.9^{\mathrm{ab}}$ & $6.4 \pm 2.0^{b}$ & $5.2 \pm 2.0^{\mathrm{ab}}$ & 6.520 & $<0.001^{\circ}$ \\
\hline Humor & $5.7 \pm 2.5$ & $3.8 \pm 2.5$ & $4.7 \pm 2.2$ & $5.2 \pm 2.0$ & $5.2 \pm 2.6$ & 2.794 & 0.027 \\
\hline Anticipation & $5.5 \pm 2.3$ & $6.4 \pm 2.4$ & $5.6 \pm 2.2$ & $6.6 \pm 1.9$ & $5.6 \pm 2.0$ & 2.460 & 0.047 \\
\hline Suppression & $5.0 \pm 1.9$ & $4.0 \pm 2.1$ & $3.6 \pm 2.0$ & $4.2 \pm 1.9$ & $3.6 \pm 1.7$ & 2.821 & 0.026 \\
\hline Rationalization & $5.2 \pm 1.7$ & $4.7 \pm 1.8$ & $5.5 \pm 1.9$ & $5.4 \pm 1.4$ & $4.7 \pm 2.0$ & 1.691 & 0.154 \\
\hline All Mature defenses & $5.1 \pm 1.3$ & $4.8 \pm 1.6$ & $5.0 \pm 1.4$ & $5.6 \pm 1.1$ & $4.9 \pm 1.3$ & 2.882 & 0.024 \\
\hline Undoing & $3.4 \pm 1.9^{\mathrm{a}}$ & $5.4 \pm 1.6^{b}$ & $4.5 \pm 2.3^{\mathrm{ab}}$ & $5.1 \pm 2.0^{b}$ & $4.6 \pm 2.2^{\mathrm{ab}}$ & 5.149 & $0.001^{*}$ \\
\hline Pseudo-altruism & $4.6 \pm 2.2^{\mathrm{a}}$ & $5.7 \pm 2.0^{\mathrm{ab}}$ & $5.4 \pm 1.9^{\mathrm{ab}}$ & $6.1 \pm 2.0^{b}$ & $6.3 \pm 2.0^{b}$ & 4.133 & $0.003^{*}$ \\
\hline Idealization & $2.3 \pm 1.7^{a}$ & $4.6 \pm 2.6^{b}$ & $3.5 \pm 2.2^{\mathrm{ab}}$ & $3.3 \pm 2.1^{\mathrm{ab}}$ & $3.2 \pm 2.2^{\mathrm{ab}}$ & 4.807 & $0.001^{*}$ \\
\hline Active reaction & $4.4 \pm 1.9$ & $5.0 \pm 2.5$ & $4.3 \pm 2.0$ & $4.4 \pm 2.0$ & $4.4 \pm 2.5$ & 0.591 & 0.669 \\
\hline All Neurotic defenses & $3.7 \pm 1.2^{a}$ & $5.2 \pm 1.4^{b}$ & $4.4 \pm 1.3^{\mathrm{ab}}$ & $4.7 \pm 1.3^{b}$ & $4.6 \pm 1.4^{b}$ & 5.021 & $<0.001^{*}$ \\
\hline Projection" & $1.5 \pm 1.0^{\mathrm{a}}$ & $5.4 \pm 2.6^{c}$ & $3.5 \pm 2.3^{b}$ & $2.3 \pm 1.6^{b}$ & $2.8 \pm 1.8^{b}$ & 20.589 & $<0.001^{\circ}$ \\
\hline Passive aggression & $2.0 \pm 1.3^{\mathrm{a}}$ & $3.8 \pm 1.9^{b}$ & $3.5 \pm 2.0^{b}$ & $3.2 \pm 1.8^{b}$ & $3.4 \pm 1.9^{b}$ & 5.056 & $0.001^{*}$ \\
\hline Acting out & $3.0 \pm 2.0^{\mathrm{a}}$ & $5.4 \pm 2.6^{b}$ & $4.7 \pm 2.5^{b}$ & $4.6 \pm 2.2^{b}$ & $5.7 \pm 1.7^{b}$ & 6.795 & $<0.001^{*}$ \\
\hline Isolation & $3.3 \pm 2.5$ & $4.6 \pm 2.8$ & $3.9 \pm 2.5$ & $3.7 \pm 2.1$ & $4.0 \pm 2.2$ & 1.295 & 0.273 \\
\hline Devaluation & $3.4 \pm 1.8$ & $4.7 \pm 2.2$ & $4.8 \pm 1.7$ & $4.0 \pm 1.7$ & $3.2 \pm 1.3$ & 5.038 & $0.001^{*}$ \\
\hline Autistic fantasy & $2.0 \pm 1.7^{\mathrm{a}}$ & $4.7 \pm 2.8^{b}$ & $4.9 \pm 2.9^{b}$ & $3.8 \pm 2.1^{b}$ & $4.2 \pm 2.4^{b}$ & 7.607 & $<0.001^{*}$ \\
\hline Denial & $2.9 \pm 1.5$ & $3.7 \pm 2.2$ & $2.9 \pm 1.4$ & $2.5 \pm 1.7$ & $2.6 \pm 1.8$ & 2.467 & 0.046 \\
\hline Displacement & $3.0 \pm 2.1$ & $4.9 \pm 2.6$ & $3.6 \pm 2.1$ & $3.7 \pm 1.9$ & $4.2 \pm 2.3$ & 3.424 & 0.010 \\
\hline Dissociation & $2.5 \pm 1.4^{\mathrm{ab}}$ & $3.6 \pm 2.3^{c}$ & $3.0 \pm 1.5^{a b c}$ & $2.2 \pm 1.4^{\mathrm{a}}$ & $3.3 \pm 2.0^{b c}$ & 5.087 & $0.001^{*}$ \\
\hline Splitting & $3.5 \pm 2.1$ & $5.2 \pm 1.8$ & $4.9 \pm 2.3$ & $4.9 \pm 1.8$ & $4.5 \pm 1.7$ & 3.746 & 0.006 \\
\hline Somatization & $3.1 \pm 2.2^{\mathrm{a}}$ & $5.8 \pm 2.4^{c}$ & $5.5 \pm 2.7^{b c}$ & $5.2 \pm 2.3^{b c}$ & $4.2 \pm 2.3^{\mathrm{ab}}$ & 7.229 & $<0.001^{*}$ \\
\hline All Immature defenses & $2.7 \pm 1.1^{\circ}$ & $4.7 \pm 1.2^{\circ}$ & $4.1 \pm 1.3^{b c}$ & $3.6 \pm 0.9^{b}$ & $3.8 \pm 0.7^{b}$ & 14.981 & $<0.001^{*}$ \\
\hline
\end{tabular}

Note: OCD - Obsessive Compulsive Disorder

${ }^{a b}$ The same letter was used when the means did not differ among groups

-Difference remained significant after Bonferroni Correction

'Dunnett's T3 Multiple Comparison

A stepwise discriminant function analysis was performed, using all defense mechanisms as predictor variables in order to identify defense mechanisms that might distinguish these five groups the four disorder groups and the control group. The discriminant analysis is shown in Table 2. The coefficients denote the correlation between the predictor variables and the functions, where the larger the coefficient, the greater is the contribution. Based on the structure correlation presented in Table 2, the first function is mainly defined by projection, the second by sublimation, the third by acting out and the fourth by somatization. These four defenses - projection, sublimation, acting out and somatization - were selected for the discriminant function analysis. The means (centroids) show which functions discriminate these groups. These values are plotted in Figure 1. Of the four discriminant functions, three were statistically significant. The first function was the major one, accounting for $63.6 \%$ of the variance. As shown in Figure 1 , this function maximally separates the control group from the MDD group, whereas the SAD, PD and OCD groups remained at an intermediate level. Function two accounts for $26.5 \%$ and mainly separates the PD group from the others. Function three accounts for $9.5 \%$ and mainly discriminates the OCD group.

In cross validation, each case is classified by the functions derived from all cases other than the case in question. In the control group, $63.9 \%$ of the cases were correctly classified as controls, compared with $53.6 \%$ correctly classified in the MDD group, $21.2 \%$ in the SAD group, $43 \%$ in the PD group, and $40.7 \%$ in the OCD group.

\section{Discussion}

According to Pollack and Andrews, we have been able to separate some specific patterns of defenses. ${ }^{5}$ In our study, anxiety patients have a similar defense profile, unlike that of MDD patients and that of controls.

Anxiety disorders and depressive disorders were both found to be associated with the use of immature defenses, but MDD patients used the maladaptive defenses more often than did the PD and OCD patients. The primary use of immature defenses by MDD patients is related to the greater use of projection. It is likely the impairment accompanied by the depressive state that influenced the use of these maladaptive defense mechanisms. This is in agreement with the findings of a previous study, in which panic disorder patients were found to differ from those with panic disorder concomitant with depression in terms of their use of immature defenses. ${ }^{7}$ Spinhoven and Kooiman also found that patients with anxiety and depressive disorders scored significantly higher for immature defense style than did controls. ${ }^{20}$ According to those

\section{Table 2 - Discriminant analysis}

\begin{tabular}{|c|c|c|c|c|}
\hline \multirow[b]{2}{*}{ Variable } & \multicolumn{4}{|c|}{ Discriminant function } \\
\hline & 1 & 2 & 3 & 4 \\
\hline Projection ${ }^{\mathrm{a}}$ & $0.951^{*}$ & -0.196 & -0.181 & 0.157 \\
\hline Autistic fantasy & $0.407^{*}$ & 0.030 & -0.110 & -0.170 \\
\hline Passive aggression & $0.384^{*}$ & 0.048 & -0.017 & -0.104 \\
\hline Displacement & $0.332^{*}$ & 0.108 & 0.103 & -0.026 \\
\hline Devaluation & $0.284^{*}$ & 0.135 & 0.123 & 0.024 \\
\hline Splitting & $0.276^{\circ}$ & 0.157 & 0.140 & -0.192 \\
\hline Isolation & $0.185^{*}$ & 0.105 & 0.028 & -0.015 \\
\hline Idealization & $0.160^{*}$ & 0.153 & 0.005 & -0.143 \\
\hline Dissociation & $0.155^{*}$ & 0.041 & -0.010 & 0.006 \\
\hline Sublimation ${ }^{a}$ & 0.072 & $0.827^{*}$ & -0.040 & 0.555 \\
\hline Humor & -0.030 & $0.304^{*}$ & -0.065 & 0.131 \\
\hline Undoing & 0.160 & $0.297^{*}$ & -0.087 & -0.116 \\
\hline Rationalization & -0.096 & $0.262^{*}$ & 0.065 & 0.141 \\
\hline Pseudo altruism & 0.103 & $0.217^{*}$ & -0.136 & -0.149 \\
\hline Anticipation & -0.085 & $0.129^{*}$ & 0.067 & -0.011 \\
\hline Acting out ${ }^{a}$ & 0.427 & 0.295 & $0.759^{\circ}$ & -0.394 \\
\hline Active reaction & 0.045 & 0.203 & -0.250 & 0.023 \\
\hline Denial & 0.056 & 0.082 & -0.100 & -0.004 \\
\hline Somatization ${ }^{a}$ & 0.440 & 0.500 & -0.408 & $-0.625^{\circ}$ \\
\hline Suppression & -0.162 & 0.125 & -0.150 & $0.184^{*}$ \\
\hline
\end{tabular}

"Variables included in the analysis

-Results equal largest absolute correlation between each variable and any discriminant function 


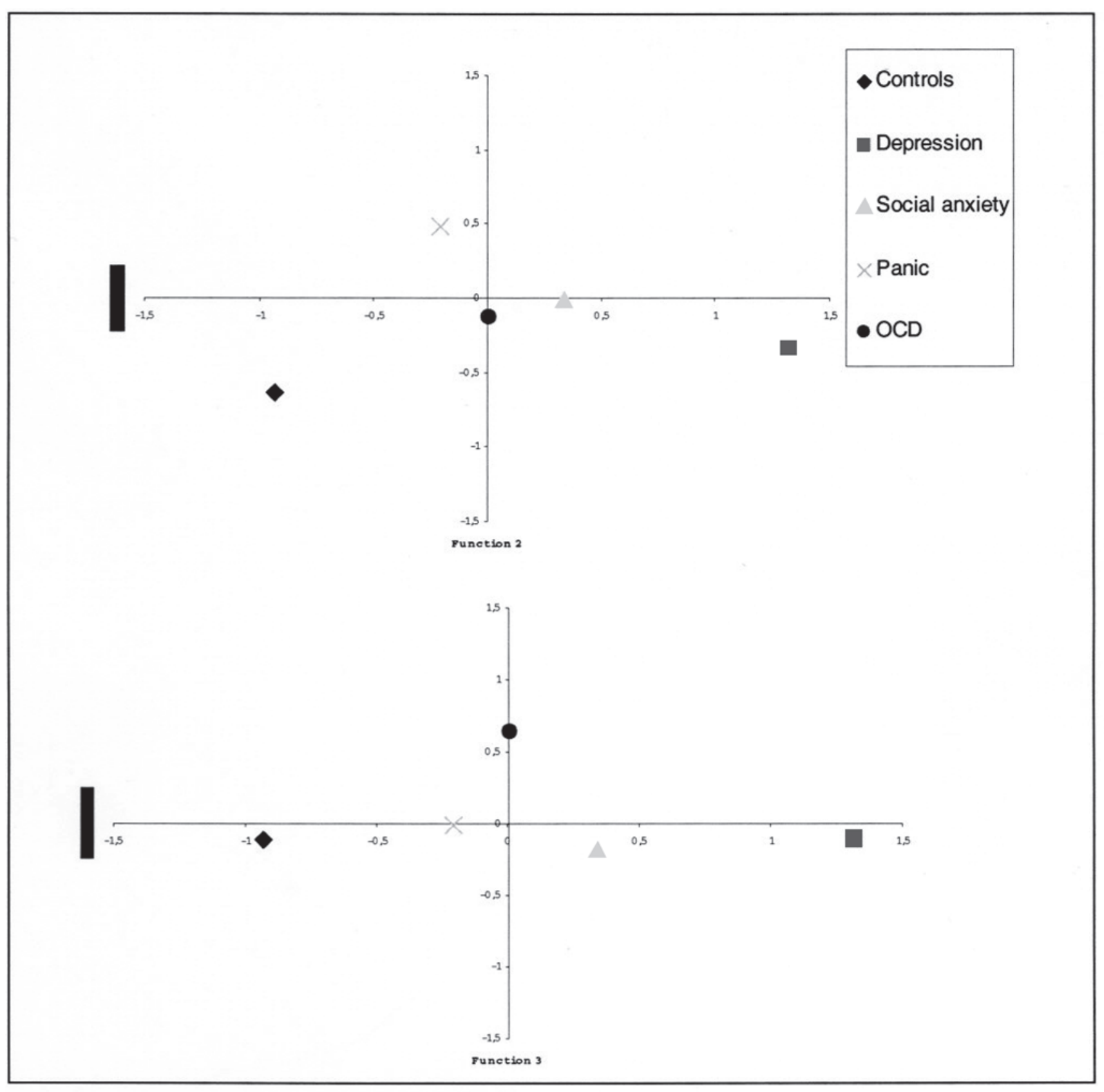

Figure 1 - Cluster plots of canonical variable mean scores by discriminant function

authors, depression was predominantly related to projection. Clinically speaking, it makes sense that defenses such as projection would become more prominent while a patient is depressed. ${ }^{15}$ According to the cognitive-behavior theory and interpersonal therapy, depressive symptoms are not only related to the individual but also projected to interpersonal relationships, the environment and the future. ${ }^{21}$ The psychoanalytic theory also relates projection to the depressive state. Freud stated that the self-criticism that characterizes this mood state is deeply related to someone else. ${ }^{22}$ In our study, projection discriminated depressive patients from controls and, at an intermediate level, from all anxiety disorder patients.

In the present study, one anxiety disorder patient could hardly be differentiated from another, probably due to the fact that they derive from the same anxiety diathesis. All presented intermediate use of projection, reflecting a lower use of immature defenses than that seen in the MDD patients. However, some idiosyncrasies must be pointed out. The PD patients differed from the others in their (greater) use of sublimation. This is in accordance with the results of a previous study in which panic disorder patients were shown to have a more adaptive profile. ${ }^{2}$ Sublimation allows indirect resolution of a conflict without adverse consequences or loss of pleasure. ${ }^{23}$ It is likely that the use of this adaptive defense partially compensates for the life impairment imposed by the mental disease. The lower use of sublimation by controls can be explained by the lack of an anxiety trigger. It is to be expected that, in a highly charged, emotional situation, such as that created by a psychiatric disorder, subjects must cope with stressors by using defense mechanisms. ${ }^{15}$ Panic disorder patients without comorbidities, who are a specific subgroup with a favorable prognosis, usually use sublimation to deal with anxiety. 
The higher use of acting out characterizes OCD patients and might be a consequence of their symptoms. Whenever they experience anxiety, which is probably triggered by an obsessive thought, they have a compulsive behavior, which means that they act out. In contrast, SAD patients can not be differentiated by their use of defenses. In our study, they presented an intermediate pattern in all factors, and this function model did not enhance the chance of correctly classifying them. Maybe some of these patients who have been diagnosed as having SAD represent an extreme of normality. In a previous study, ${ }^{24}$ it was suggested that social anxiety can be a normal, species-typical, designed response to specific trigger situations; one that is roughly normally distributed in temperamental intensity. Therefore, many individuals whom the DSM-IV potentially classifies as suffering from social phobia are probably not disordered but might have a harm-avoidant temperament. ${ }^{14}$ Perhaps the impairment related to SAD or to the harm-avoidant temperament developed early in life prevents these individuals from establishing the neurotic pattern seen in those suffering from the other anxiety disorders. Further studies focusing on the severity and the treatment outcome of the disorder are necessary in order to elucidate whether this population presents a particular defense pattern.

Among the limitations of the present study is the use of a self-report questionnaire that depends on participant selfknowledge and revelation. The instrument used provides an indirect measure of defenses, which are unconscious intrapsychic processes. In addition, since this was a crosssectional study, we are unable to infer a cause-and-effect relationship. Recent studies have shown that, although panic disorder patients use more immature and neurotic defenses than do controls, they do not differ from controls during remission (after pharmacological treatment). ${ }^{14}$ Further studies are warranted in order to examine whether the defense mechanisms measured were state- or trait-dependent. The defense mechanisms and clinical diagnoses are likely to be different patterns of a similar psychopathology. This is in agreement with the findings of some clinical studies in which defense mechanisms were related to treatment outcome. ${ }^{9,13,25}$ The definition of distinct groups with similar clinical profiles could have significant implications for specific management. ${ }^{26}$ Therefore, greater knowledge of these particular patterns might lead to specific treatment interventions.

\section{Conclusions}

The results of the present study show that some psychiatric diagnoses are related to particularities in the use of the defense mechanisms. This finding is different from that of our previous analysis, in which we found no differences among patients. Excluding patients with comorbidities allowed us to evaluate psychiatric diagnoses in their pure form during the acute symptomatic phase. Finally, PD, OCD and MDD diagnoses seem to modify neurotic and immature defenses, whereas a diagnosis of SAD seems to modify only the immature defenses. However, depressive disorder has a greater influence on the use of immature mechanisms.

\section{Acknowledgments}

The authors wish to express their esteem for Andréa Raffin, Marcelo Basso and Marcelo Berlim.

\section{References}

1. Blaya C, Kipper L, Blaya Perez Filho J, Manfro GG. Mecanismos de defesa: uso do Defensive Style Questionnaire. Rev Bras Psicoter. 2003;5(1):67-80.

2. Vaillant GE. Theoretical hierarchy of adaptive ego mechanisms: a 30-year follow-up of 30 men selected for psychological health. Arch Gen Psychiatry. 1971;24(2):107-18.

3. Bond MP, Vaillant JS. An empirical study of the relationship between diagnosis and defense style. Arch Gen Psychiatry. 1986;43(3):285-8.

4. Laplanche J, Pontalis JB. Vocabulário da psicanálise. 11a ed. São Paulo: Martins Fontes; 1991

5. Pollock C, Andrews G. Defense styles associated with specific anxiety disorders. Am J Psychiatry. 1989;146(11):1500-2.

6. Yuan $\mathrm{Y}$, Zhan $\mathrm{X}, \mathrm{Wu}$ A. Defense mechanisms in comorbid anxiety and depression. Chinese Ment Health J. 2002;16:86-8.

7. Kipper L, Blaya C, Teruchkin B, Heldt E, Isolan L, Mezzomo K, Bond M, Manfro GG. Brazilian patients with panic disorder: the use of defense mechanisms and their association with severity. J Nerv Ment Dis. 2004;192(1):58-64.

8. Bonsack C, Despland JN, Spagnoli J. The French version of the Defense Style Questionnaire. Psychother Psychosom. 1998;67(1):24-30.

9. Hoglend P, Perry JC. Defensive functioning predicts improvement in major depressive episodes. J Nerv Ment Dis. 1998;186(4):238-43.

10. Akkerman K, Carr VJ, Lewin T. Changes in ego defenses with recovery from depression. J Nerv Ment Dis. 1992;180(10):634-8.

11. Akkerman K, Lewin TJ, Carr VJ. Long-term changes in defense style among patients recovering from major depression. J Nerv Ment Dis. 1999;187(2):80-7.

12. Kneepkens RG, Oakley LD. Rapid improvement in the defense style of depressed women and men. J Nerv Ment Dis. 1996;184(6):358-61.

13. Heldt E, Manfro GG, Kipper L, Blaya C, Maltz S, Isolan L, Hirakata VN, Otto MW. Treating medication-resistant panic disorder: predictors and outcome of cognitive-behavior therapy in a Brazilian public hospital. Psychother Psychosom. 2003;72(1):43-8.

14. Kipper L, Blaya C, Teruchkin B, Heldt E, Isolan L, Mezzono K, Bond M, Manfro GG. Evaluation of defense mechanisms in adult patients with panic disorder: before and after treatment. J Nerv Ment Dis. 2005;193(9):619-24.

15. Bond M. Empirical studies of defense style: relationships with psychopathology and change. Harv Rev Psychiatry. 2004;12(5):263-78.

16. Amorim P. Mini International Neuropsychiatric Interview (MINI): validação de entrevista breve para diagnóstico de transtornos mentais. Rev Bras Psiquiatr. 2000;22(3):106-15.

17. Sheehan DV, Lecrubier Y, Sheehan KH, Amorim P, Janavs J, Weiller E, Hergueta T, Baker R, Dunbar GC. The Mini-International Neuropsychiatric Interview (M.I.N.I.): the development and validation of a structured diagnostic psychiatric interview for DSMIV and ICD-10. J Clin Psychiatry. 1998;59(Suppl 20):22-33.

18. Blaya C, Kipper L, Heldt E, Isolan L, Ceitlin LH, Bond M, Manfro GG. Brazilian Portuguese version of the Defensive Style Questionnaire (DSQ-40) for defenses mechanisms measure: a preliminary study. Rev Bras Psiquiatr. 2004;26(4):255-8.

19. Andrews G, Singh M, Bond M. The Defense Style Questionnaire. J Nerv Ment Dis. 1993;181(4):246-56.

20. Spinhoven P, Kooiman CG. Defense style in depressed and anxious psychiatric outpatients: an explorative study. J Nerv Ment Dis. 1997;185(2):87-94.

21. Beck AT, Rush AJ, Shaw BF, Emery G. Cognitive Therapy of Depression. New York: Guilford; 1979.

22. Freud S. Luto e melancolia. In: Edição Standard Brasileira das Obras Completas de Sigmund Freud. Rio de Janeiro: Imago; 1917. p. 275-91.

23. Vaillant GE. Adaptative mental mechanisms: their role in a positive psychology. Am Psychologist. 2000;55(1):89-98.

24. Wakefield JC, Horwitz AV, Schmitz MF. Are we overpathologizing the socially anxious? Social phobia from a harmful dysfunction perspective. Can J Psychiatry. 2005;50(6):317-9.

25. Birmes P, Hazane F, Calahan S, Sztulman H, Schmitt L. [Defense mechanisms and the prediction of PTSD]. Encephale. 1999;25(5):443-9.

26. Rapeli CB, Botega NJ. Clinical profiles of serious suicide attempters consecutively admitted to a university-based hospital: a cluster analysis study. Rev Bras Psiquiatr. 2005;27(4):285-9. 